OPEN ACCESS

Edited by: Mingming $L u$,

University of Cincinnati, United States

Reviewed by:

Rahul Kumar,

Arizona State University, United States

Shixuan Zeng,

Bettergy, United States

*Correspondence:

Siang-Piao Chai

chai.siang.piao@monash.edu

Specialty section:

This article was submitted to Sustainable Process Engineering,

a section of the journal

Frontiers in Chemical Engineering

Received: 21 July 2021 Accepted: 25 October 2021 Published: 11 November 2021

Citation:

Gui MM, Lee WPC, Putri LK, Kong XY,

Tan L-L and Chai S-P (2021) Photo-

Driven Reduction of Carbon Dioxide: A

Sustainable Approach Towards

Achieving Carbon Neutrality Goal.

Front. Chem. Eng. 3:744911.

doi: 10.3389/fceng.2021.744911

\section{Photo-Driven Reduction of Carbon Dioxide: A Sustainable Approach Towards Achieving Carbon Neutrality Goal}

\author{
Meei Mei Gui ${ }^{1}$, W.P. Cathie Lee ${ }^{2}$, Lutfi Kurnianditia Putri ${ }^{3}$, Xin Ying Kong ${ }^{4}$, Lling-Lling Tan ${ }^{5}$ \\ and Siang-Piao Chai ${ }^{5 *}$
}

${ }^{1}$ School of Chemistry and Chemical Engineering, Queen's University Belfast, Belfast, United Kingdom, ${ }^{2}$ Entropic Interface Group, Engineering Product Development, Singapore University of Technology and Design, Singapore, Singapore, ${ }^{3}$ Low Carbon Economy (LCE) Research Group, School of Chemical Engineering, Universiti Sains Malaysia, Nibong Tebal, Malaysia, ${ }^{4}$ Division of Chemistry and Biological Chemistry, School of Physical and Mathematical Sciences, Nanyang Technological University, Singapore, Singapore, ${ }^{5}$ Multidisciplinary Platform of Advanced Engineering, Chemical Engineering Discipline, School of Engineering, Monash University, Bandar Sunway, Malaysia

The photo-driven reduction of carbon dioxide $\left(\mathrm{CO}_{2}\right)$ into green and valuable solar fuels could be a promising solution to simultaneously address energy- and environmentalrelated problems. This approach could play an integral role in achieving a sustainable energy economy by closing the carbon cycle and allowing the storage and transportation of intermittent solar energy within the chemical bonds of hydrocarbon molecules. This Perspective discusses the latest technological advancements in photo-driven $\mathrm{CO}_{2}$ conversion via various pathways, namely photocatalysis, photoelectrocatalysis and photovoltaic-integrated systems. In addition to providing an outlook on unresolved issues concerning the said technologies, this Perspective also spotlights new trends and strategies in the structural engineering of materials to meet the demands for prominent $\mathrm{CO}_{2}$ photoreduction activity as well as spearhead the ground-breaking advances in the field that lead to the translation of $\mathrm{CO}_{2}$ photo-driven technologies from the laboratory to industrial-scale applications.

Keywords: carbon dioxide, photocatalysis, photoelectrochemical, photovoltaic, environmental remediation

\section{INTRODUCTION}

Greenhouse gases (GHG) emission has been identified as the major cause that leads to climate change and has remained as the primary challenge in the effort to control the pace of global warming. The United Nations Framework Convention on Climate Change (UNFCCC) entered into force in 1994 with a pivotal role to oversee and control the emission of GHG as a global effort. In the same year, the impact of climate change and the need for mitigations to tackle this issue were recognized and highlighted for the first time in the Convention. Figure 1A depicts key development of climate change actions by UNFCCC since its establishment. The Kyoto Protocol was initiated in 1997 with all party members came into agreement to limit and reduce the emission of GHG with individual targets tailored for their respective countries. The initiative only entered into force 8 years later and was amended in 2012 (known as the Doha Amendment) with emission targets renewed for the second commitment period from 1 January 2013 to 31 December 2020 (United Nations Climate Change). On the other hand, Copenhagen Accord was established in December 2009 where a target of global 
A Doha Amendment,

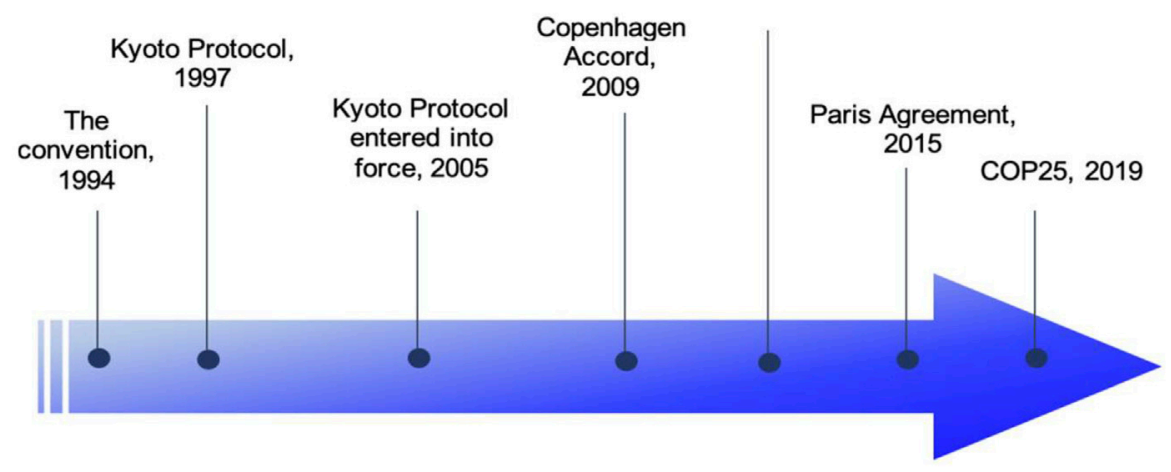

B

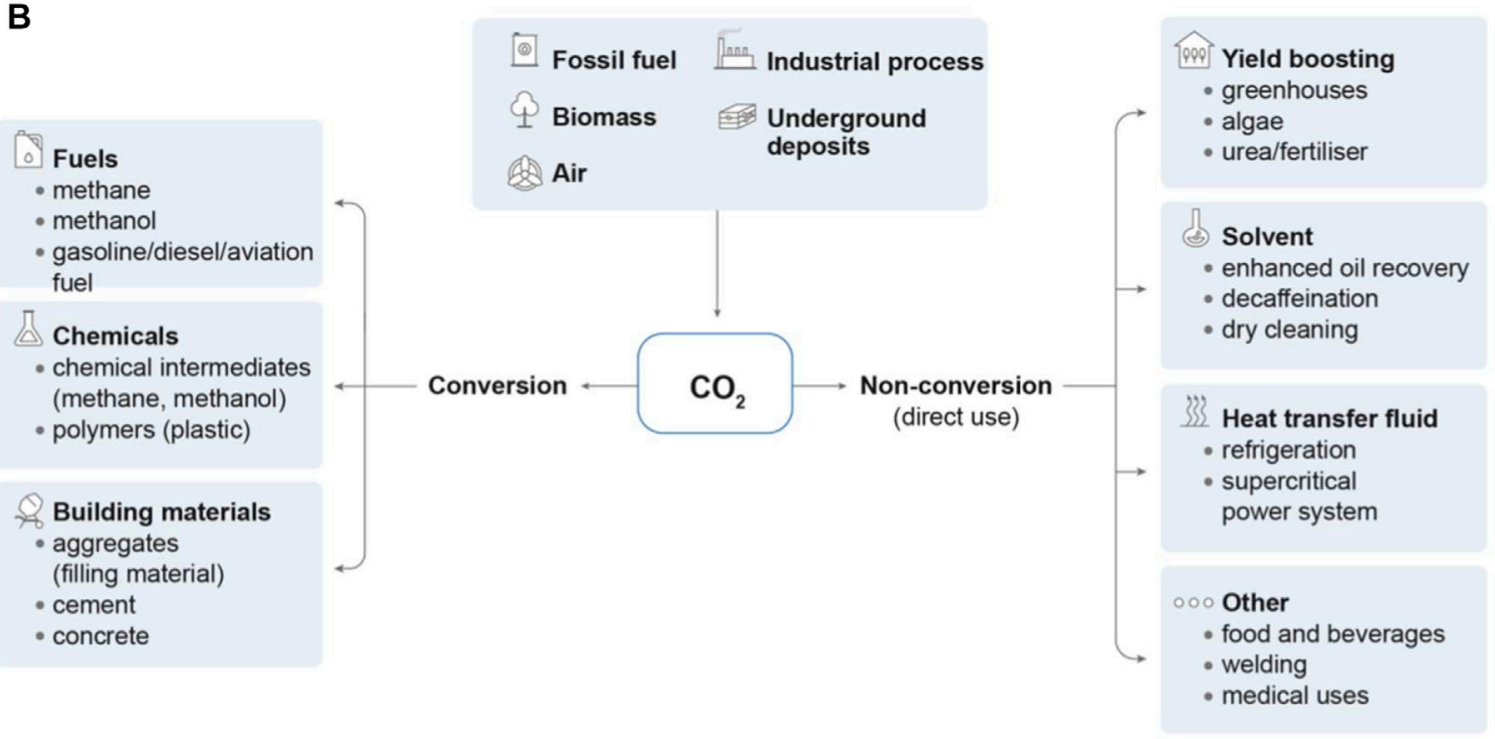

FIGURE 1 | (A) Timeline of major UNFCCC actions on climate change. (B) Potential pathways for $\mathrm{CO}_{2}$ utilization (IEA, 2019 ).

temperature rises of not more than $2 \mathrm{C}$ above pre-industrial level was introduced (United Nations Climate Change, 2009). The global target was highlighted again in Paris Agreement, 2015, to drive social and economic transformation to control global warming at preferably $1.5 \mathrm{C}$ above pre-industrial levels (United Nations Climate Change). In response to the Paris Agreement, both EU and United Kingdom have set their targets to achieve at least 55 and $68 \%$ reduction in GHG emission, respectively by 2030 with the final goal of zero-carbon emission by 2050 (Gov, 2020; European Commission). This ambitious zero-carbon emission target requires effort from several stakeholders across the nations, up from technology advancement and transformation of current industrial activities down to the reforming of policies and regulations to facilitate socioeconomic development sectors associated with GHG emissions.

To control the emission of carbon dioxide $\left(\mathrm{CO}_{2}\right)$, the main culprit of global GHG emission, new technology pathways related to $\mathrm{CO}_{2}$ capture, utilization and sequestration (CCUS) have been widely studied over the past decades. Figure 1B illustrates the potential pathways for the utilization of $\mathrm{CO}_{2}$ in the industry. In general, $\mathrm{CO}_{2}$ collected on-site can be either: 1) directly used as a heat transfer fluid or feedstock/solvent in manufacturing processes or; 2) converted into other derivatives, such as fuels, hydrocarbons, and building materials following respective chemical synthesis routes. Currently, the established technologies are carbon capture with amine process, direct capture from air with underground deposit, and carbon capture integrated with bioenergy plant (IEA, 2021a). According to the recent report by IEA, the overall cost of carbon capture can be in a broad range of USD15-25/t $\mathrm{CO}_{2}$ (for CCUS from natural gas processing) to USD130-340/t $\mathrm{CO}_{2}$ (for direct capture), subject to the quality of $\mathrm{CO}_{2}$ streams and the technology applied (IEA, 2021). These technologies are costly but necessary to achieve a zero-carbon emission goal. Therefore, the continuous advancement in CCUS technologies is an on-going process to improve their availability and cost effectiveness for large-scale, practical deployment. 


\section{RECENT TECHNOLOGICAL ADVANCEMENTS IN THE PHOTOREDUCTION OF $\mathrm{CO}_{2}$}

The transformation of $\mathrm{CO}_{2}$ into energy bearing hydrocarbon compounds has gained incessant research interest in recent years (Creutzig, et al., 2017; Alsayegh et al., 2020). Converting $\mathrm{CO}_{2}$ generated from a combustion process into hydrocarbon fuels offers attractive solution to close the carbon-fuel cycle (Ulmer et al., 2019). Ideally, for the derivation of completely renewable hydrocarbon fuels from $\mathrm{CO}_{2}$, the entire synthesis route should have minimal carbon emission and be free from fossil fuel usage. With this aim, much attention has been placed on using solar energy as the future energy source. Nevertheless, the practical implementation of $\mathrm{CO}_{2}$ photoreduction technologies necessitates the development of highly efficient, robust, photo-driven materials and systems; these have been hot research areas in recent years. Thus, in this perspective, the latest technological advances in the photo-driven reduction of $\mathrm{CO}_{2}$ are summarized and discussed with comments of their respective advantages and existing limitations. The three primary $\mathrm{CO}_{2}$ reduction systems covered are: 1) the photocatalytic $\mathrm{CO}_{2}$ reduction; 2) the photoelectrochemical (PEC) pathway as well as 3) the photovoltaic-integrated systems.

\section{Photocatalytic $\mathrm{CO}_{2}$ Reduction}

The efficiency of photocatalytic $\mathrm{CO}_{2}$ reduction lies in the design of the photocatalyst. Therefore, it is of paramount importance to tailor the electronic structures of photocatalysts, with efforts to modulate the reaction paths and activation energy barriers, thereby enhancing the photoactivity and product selectivity (Wang H.-N. et al., 2021). In recent years, significant research progress has been witnessed in photocatalysis. A myriad of novel photocatalysts with $0 \mathrm{D}$ (zero-dimensional, i.e., quantum dots), 1D (one-dimensional, i.e., nanotubes, nanorods), 2D (twodimensional, i.e., atomic layers, nanosheets, nanoplates) and 3D (three-dimensional, i.e., hollow nanostructures, nanospheres, microspheres) structures have been developed (; Kong et al., 2017; Kong et al., 2019; He et al., 2019; Kong et al., 2020; Sun et al., 2020; Wang J. et al., 2020; Ke et al., 2021; Li L. et al., 2021). The photoactivities are highly dependent on the architectures of the photocatalysts as the light trapping capability, surface active sites, electron-hole pairs separation and transportation pathways of photocatalysts are greatly affected by the structures. To improve the photoresponse of catalysts, a number of strategies have been adopted to reduce the bandgap of photocatalysts by integration of dopants, sensitizers, co-catalysts, heteroatoms or inducing surface defects (Chen et al., 2021; Chen et al., 2020; Lee et al., 2020; Miao et al., 2021; Pan et al., 2021). For instance, introducing oxygen vacancy (OV) onto bismuth tungstate could expand the light absorption spectrum of the photocatalyst from UV to near infrared (Kong et al., 2016). The OV-induced defect states play indispensable role to trap photoinduced electrons, hence improving the electron-hole pair separation and inhibiting the direct recombination of photogenerated charge carriers. In this photocatalyst structure, near infrared light was harvested through sub-bands excitation from $\mathrm{OV}$-induced defect states to the conduction band of bismuth tungstate (Figure 2A). To promote the separation and transportation of photoinduced charge carriers, Type-II, $\mathrm{Z}$-scheme or $\mathrm{p}$-n heterojunctions are often introduced to the composite photocatalysts to prolong the lifetime of charge carriers so that more electrons can take part in the $\mathrm{CO}_{2}$ reduction reaction (Jiang et al., 2020; Li S. et al., 2021; Wu et al., 2021). Since $\mathrm{CO}_{2}$ reduction can only take place on the surface active sites, many recent researches focus on crystal facet engineering in order to maximize the exposure of most active facets (Kong et al., 2018; Jatav et al., 2021). Besides, decreasing the thickness of 2D materials to ultrathin-nanoscale or even atomic layers can endow ultrafast transportation of charge carriers from interior to the surface of photocatalysts along with large exposure of active sites to boost $\mathrm{CO}_{2}$ adsorption and activation (Han et al., 2021; Teh et al., 2021).

Other than the conventional semiconductor photocatalysts, molecular photocatalysts have received much attention in the past few years. In another reported work, $\mathrm{CO}$ production rate of up to $10,162 \mu \mathrm{mol} \mathrm{g}^{-1} \mathrm{~h}^{-1}$ was obtained using COF-367-Co nanosheets under visible light illumination with $\left[\mathrm{Ru}(\mathrm{bpy})_{3}\right] \mathrm{Cl}_{2}$ (bpy $=2,2^{\prime}$-bipyridine) as the photosensitizer (Figure 2B) (Liu et al., 2019). The Photosensitizer plays a pivotal role where it absorbs incident light and converts it to photon energy that activates the nearby photocatalyst. Very recently, a molecularly engineered, scalable photocatalyst sheet with solar-to-formate conversion efficiency of $0.08 \pm 0.01 \%$ and product selectivity of $97 \pm 3 \%$ for formate were reported. Notably, in this setup, the photoreduction of $\mathrm{CO}_{2}$ was realized without using any sacrificial reagents; however, the photocatalytic system is complex, which comprises of $\mathrm{Rh}, \mathrm{La}, \mathrm{SrTiO}_{3}, \mathrm{BiVO}_{4}, \mathrm{RuO}_{2}, \mathrm{Au}$, and phosphonated cobalt(II) bis(terpyridine) (Wang Q. et al., 2020).

\section{PEC $\mathrm{CO}_{2}$ Reduction}

PEC $\mathrm{CO}_{2}$ reduction, which uses electricity as an aide, enables higher conversion efficiencies and offers more design room owing to the wider selection of exploitable materials and configurations. For a commercially competitive device, PEC materials and cell design should approach high product selectivity with photocurrent of $7 \mathrm{mAcm}^{-2}$ (corresponding to a $10 \%$ solar-tofuel efficiency) and minimum bias requirement in the simplest possible system (Kumaravel et al., 2020). Although singlesemiconductor configurations in photoanode- or photocathode-driven $\mathrm{CO}_{2}$ reduction reactions provide the greatest simplicity, they face elevated requirements, needing larger biases to achieve high system efficiencies (Kim J. H. et al., 2019). It is worth recognizing that higher photocurrent and lower onset potential values have generally been linked to catalytically-active materials which can overcome the high kinetic overpotential of the $\mathrm{CO}_{2}$ reduction half-reaction, and by a lesser degree, the optical and charge transport properties of the photoelectrode. Single-junction expensive PV-grade materials such as Si (Fung et al., 2020; Hu et al., 2018; Rao et al., 2018), GaN (DuChene et al., 2018; Sekimoto et al., 2016), InP (Kaneco et al., 2006a; Kaneco et al., 2006b; Qiu et al., 2015; Zeng et al., 2015) and ZnTe (Jang et al., 2014; Jang et al., 2015) with excellent optical and charge transport properties have been extensively 
A

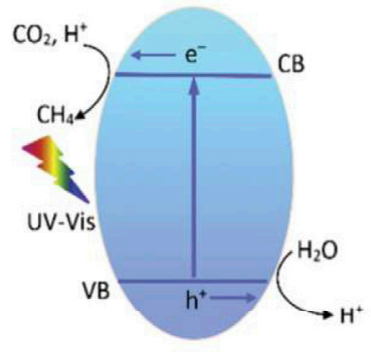

B
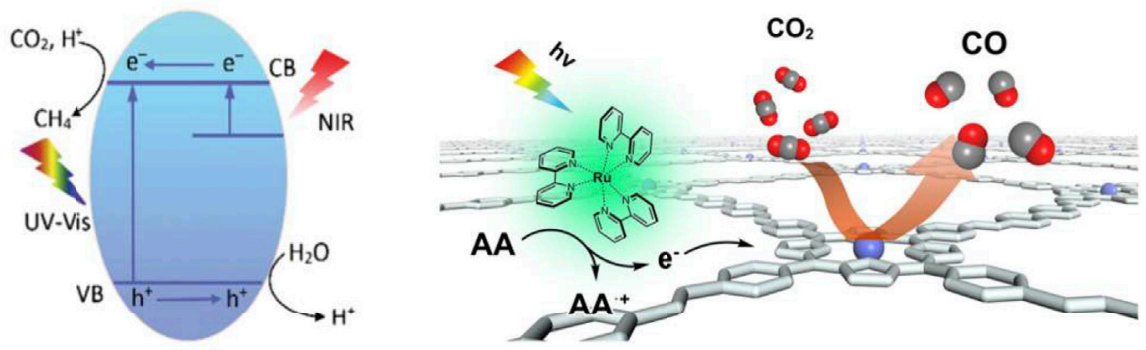

D

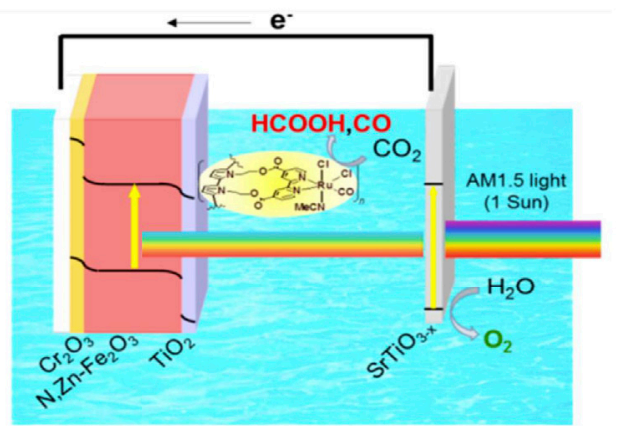

F

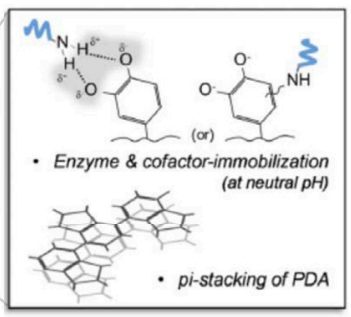

E

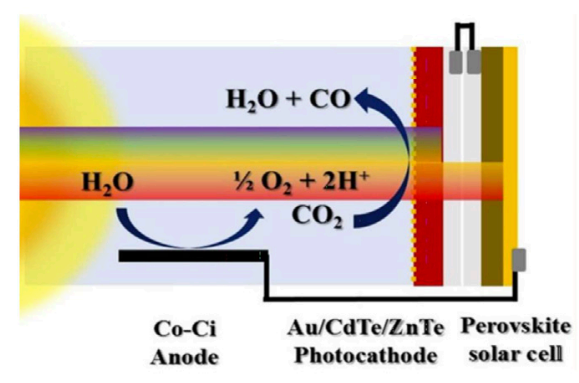

C

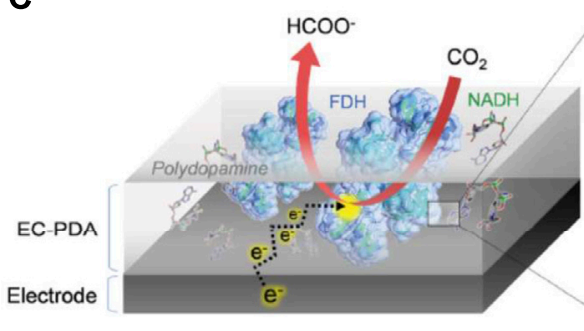

G

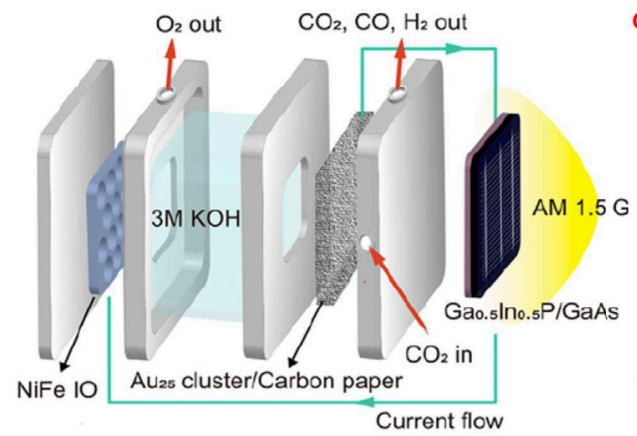

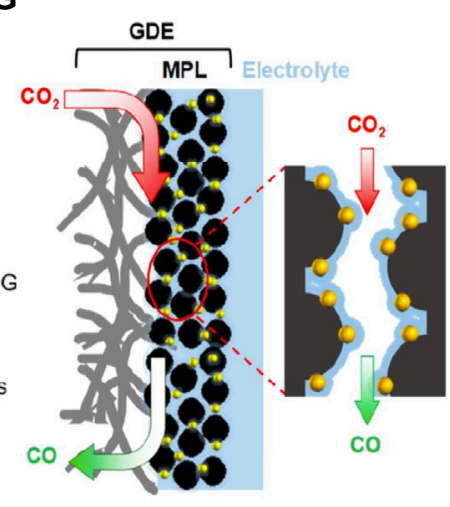

FIGURE 2 | (A) Mechanisms for photocatalytic $\mathrm{CO}_{2}$ reduction over pristine and oxygen-deficient bismuth tungstate (Kong et al., 2016), (B) Mechanisms for photoreduction of $\mathrm{CO}_{2}$ into $\mathrm{CO}$ over COF-367-Co nanosheets with [Ru(bpy) $]^{2+}$ as photosensitizer and ascorbic acid as electron donor (Liu et al., 2019). (C) Biocathode thin film derived from a polydopamine (PDA) matrix copolymerized with an enzyme (FDH) and its cofactor (NADH) (Lee et al., 2016), (D) Dual-electrodes PEC-PEC tandem cell consisting a $\mathrm{SrTiO}_{3-x}$ photoanode and $\mathrm{Ru}(\mathrm{MeCN}) \mathrm{CO}_{2} \mathrm{C} 3 \mathrm{Py}-\mathrm{P} / \mathrm{TiO} 2 / \mathrm{N}, \mathrm{Zn}-\mathrm{Fe}_{2} \mathrm{O}_{3} / \mathrm{Cr}_{2} \mathrm{O}_{3}$ photocathode (Sekizawa et al., 2018). (E) PV-PEC tandem cell comprising an Au-CdTe@ZnTe@ZnO NR photocathode-perovskite solar cell and a cobalt bicarbonate (Co-Ci) anode (Jang et al., 2016), (F) PV-GDE-based flow electrolyser cell employing NiFe anode and $\mathrm{Au}_{25}$ cathode (Kim B. et al., 2019), (G) Schematic of $\mathrm{CO}_{2}$ reduction reaction on $\mathrm{Au} \mathbf{2}_{25}$-anchored $\mathrm{GDE}(\mathrm{MPL}=$ microporous layer) (Cheng et al., 2020).

studied. Nevertheless, these materials possess poor catalytic sites for $\mathrm{CO}_{2}$ reduction, which usually offer little to no redeeming improvements in the PEC activity as compared to those of more catalytically-active copper-based (Ghadimkhani et al., 2013; Won et al., 2014; de Brito et al., 2015; Kang et al., 2015; Kang and Park, 2017; Lee et al., 2018) or molecular metal-complex (Arai et al., 2011; Jeon et al., 2014; Huang et al., 2016; Kumagai et al., 2017) systems, whose activities have hitherto remained unparalleled.

Recently, integrating microbes and enzymes into biocathodes (Figure 2C) have shown massive success in lowering bias requirements due to their innate capacity to catalyze a range of $\mathrm{CO}_{2}$ metabolic processes (Fu et al., 2018; Kuk et al., 2019; Sokol et al., 2018; Xu et al., 2021). Despite the high bias requirement in single-junction configurations, bias-free photoanode-driven $\mathrm{CO}_{2}$ reduction were realized by the microbial $\mathrm{TiO} /$ CdS-Methanobacterium (Xiao et al., 2020) and enzymatic $\mathrm{CoPi} / \mathrm{BiVO}_{4}-\mathrm{PDA} / \mathrm{NADH} / \mathrm{FDH}$ (Lee et al., 2016) hybrid systems, reaching unprecedented single-junction solar conversion efficiencies of 1.28 and $0.042 \%$, respectively. Moreover, higher conversion efficiencies and lower biases have also been achieved in the more complex, dual photoanodephotocathode tandem configurations, owing to their improved spectral absorption, cumulative photo-potential and Z-schematic band arrangement which better meets the voltage and band-edge requirements for $\mathrm{CO}_{2}$ reduction. A seminal work by Arai et al. reported among the highest solar-to-chemical conversion 
efficiency of $0.14 \%$ to formate, which approaches that of the biological plant switchgrass $(0.2 \%)$, using a $\mathrm{SrTiO}_{3}$ photoanode and InP[RuCP] photocathode (Arai et al., 2013). While more recently, the combination of $\mathrm{SrTiO}_{3-\mathrm{x}}$ photoanode and $\mathrm{Ru}(\mathrm{MeCN}) \mathrm{CO}_{2} \mathrm{C} 3 \mathrm{Py}-\mathrm{P} / \mathrm{TiO}_{2} / \mathrm{N}, \mathrm{Zn}-\mathrm{Fe}_{2} \mathrm{O}_{3} / \mathrm{Cr}_{2} \mathrm{O}_{3}$ photocathode (Figure 2D) can yield a comparable efficiency of $0.15 \%$, by alternately employing more abundant and cheaper multilayer metal oxides with efficient interfaces (Sekizawa et al., 2018).

\section{Photovoltaic-Assisted $\mathrm{CO}_{2}$ Reduction}

Photovoltaic-photoelectrochemical (PV-PEC) schemes are another attractive option to achieve spontaneous $\mathrm{CO}_{2}$ reduction at the expense of higher system complexity. This is since voltage requirement for $\mathrm{CO}_{2}$ reduction can be offset by the additional bias generated from the $\mathrm{PV}$ cell. The $\mathrm{WO}_{3} /$ dyesensitized solar cells tandem photoanode with $\mathrm{Cu}_{\mathrm{x}} \mathrm{O}$ wirearray cathode, is by far, one of the most efficient PV-PEC systems with a solar-to-CO efficiency of $2.5 \%$ (Nath et al., 2016). On the other hand, an Au-decorated triple layered ZnO@ZnTe@CdTe core-shell nanoarray photocathode in tandem with $\mathrm{CH}_{3} \mathrm{NH}_{3} \mathrm{PbI}_{3}$ perovskite solar cell and a $\mathrm{Co}-\mathrm{Ci}$ anode, which produced $\mathrm{CO}$ with a $0.35 \%$ conversion efficiency, was reported (Figure 2E) (Jang et al., 2016). Balancing light absorbance in the PV and PEC cell however remains a challenging aspect which has prohibitively restricted conversion efficiencies to mostly below $<0.1 \%$ (Kuk et al., 2019; Zhou et al., 2019; Andrei et al., 2020). Zhou et al., on the other hand, reported an exceptionally high efficiency of $\sim 10 \%$ by PVPEC using a buried III-V tandem photoanode GaAs/InGaP/ $\mathrm{TiO}_{2} / \mathrm{Ni}$ and a $\mathrm{Pd} / \mathrm{C}$ cathode by means of a bipolar membrane (Zhou et al., 2016). The use of a bipolar membrane enabled the seamless coupling between two electrodes and electrolytes at different $\mathrm{pH}$ values, each optimized respectively for oxygenevolution ( $\mathrm{pH}$ 13.7) and $\mathrm{CO}_{2}$ reduction reaction $(\mathrm{pH} 8.0$ ), which overall lowered the combined cell overvoltage.

A higher efficiency range of 5-20\% has usually been acquired in PV-EC configurations, where semiconductor-liquid-junctions are eliminated (Schreier et al., 2015; Bullock et al., 2017; Arai et al., 2019). Some notable works were by Schreier et al. which attained a solar-to-CO efficiency of $13.4 \%$ by pairing a threejunction $\mathrm{GaInP} / \mathrm{GaInAs} / \mathrm{Ge} \mathrm{PV}$ cell to a $\mathrm{CO}_{2}$-to-CO electrolyser equipped with a bipolar membrane (Schreier et al., 2017). More recently, the applications of gas diffusion electrodes (GDE) in electrolyser flow cell designs have afforded record-breaking efficiencies. The use of GDEs permit a semi-gas-phase operation at the cathode compartment, allowing higher current densities by circumventing the mass-transfer limitation of $\mathrm{CO}_{2}$ in aqueous system. Through directly connecting a highefficiency PV cell and a GDE-based flow electrolyser (Figures 2F,G), Kim B. et al. (2019) and Cheng et al. (2020) have achieved a $\mathrm{CO}_{2}$-to-CO efficiency of as high as 18.0 and $19.1 \%$, respectively. Though it should be noted that while higher efficiencies have been achieved, this comes at the price of greater device complexity and cost, and a techno-economic assessment is required to ensure that these enhanced performances offer worthwhile advantages over the simpler single-junction devices. Ultimately, the ideal choice for PEC materials and cell design should strike the perfect balance between maximizing conversion efficiency and minimizing system cost.

\section{CHALLENGES AND FUTURE PROSPECTS}

Desptite its great significance, the photoreduction technology is still far from commercialization and the complex reaction system curtails its practical applications. Technology readiness level (TRL), a measurement system that assesses the maturity level of a particular technology, can be used as an indicator to gauge the readiness of the photoreduction technology for full commercial deployment. Currently, the TRL of the photoreduction of $\mathrm{CO}_{2}$ remains low at TRL 3 to 4 (Jarvis and Samsatli, 2018). Most of the research findings reported are limited to the laboratory-scale and revolve around the development of photocatalytic materials. There are only a handful of work on pilot-scale operations at low capacity. To make this technology feasible for commercial scale production, the technology must achieve at least TRL 6 or 7 for demonstrating in the relevant environment. It is anticipated that at least five to ten years of further research is needed before carbon photoreduction technology can be practically deployed (The Global $\mathrm{CO}_{2}$ Initiative, 2016).

Another key aspect is the fabrication of catalyst from inexpensive, non-toxic and abundantly available elements. To date, a diverse range of photo(electrochemical)catalysts has been reported to be efficient for $\mathrm{CO}_{2}$ photoreduction in various reactor set-ups. The vast majority of these materials are carefully tailored using multiple dopants to achieve high efficiency and selectivity. The introduction of rare earth elements as dopants or co-catalysts, such as $\mathrm{Ce} / \mathrm{TiO}_{2}$ (Xiong et al., 2015), monometallic cerium layered double hydroxides (Ye et al., 2017), La/g-CNT (Muhammad et al., 2020), $\mathrm{La}_{0.225} \mathrm{Bi}_{0.775} \mathrm{O}_{1.5}$ (Wang Y. et al., 2021) and yttrium-doped H-Titanate (Lu et al., 2019), $\operatorname{Re}(\mathrm{CO})_{3}$ (bpy)Cl (Adams et al., 2018) etc., will increase the overall cost of the photoreduction and pose environmental issues.

Another challenge of $\mathrm{CO}_{2}$ photoreduction lies within the product selectivity and yield. Taking methane $\left(\mathrm{CH}_{4}\right)$ as an example, $\mathrm{CO}_{2}$ photoreduction under visible light irradiation could yield 3-12 times more $\mathrm{CO}$ than $\mathrm{CH}_{4}$. (Cheng et al., 2017; Raziq et al., 2017; Thompson et al., 2020). The stark difference in yield is attributed to the preferred formation of $\mathrm{CO}$ over $\mathrm{CH}_{4}$, as the former only requires two electrons while the latter requires eight. Interestingly, other researchers have also reported contrasting results where a higher yield of $\mathrm{CH}_{4}$ was observed over CO (Wang et al., 2021; Wu et al., 2021). The difference in the results is due to the unique characteristics of the photocatalysts used. This prompts the need for selectivity studies to tailor the photocatalyst to maximise its yield for the desired products. Additionally, water plays an essential role in $\mathrm{CO}_{2}$ conversion as it serves as both the electron and proton donor. Therefore, in catalytic $\mathrm{CO}_{2}$ reduction reactions, be it photocatalysis, PEC or PV-EC, the competing reaction of water reduction is fundamentally unavoidable. The aforementioned reaction effectively reduces the yield of the 
intended product by reducing the electrons available for $\mathrm{CO}_{2}$ photoreduction.

The $\mathrm{CO}_{2}$ photoreduction pathway can be regarded as a green process since the reaction is merely powered by light energy. This, however, poses an important challenge to the commercialization of the technology. The incident light intensity is known to be one of the most important factors that controls the efficiency of a $\mathrm{CO}_{2}$ photoreduction process (Tan et al., 2017). As such, the potential for industrial-scale operation of $\mathrm{CO}_{2}$ photoreduction is largely constrained by regional solar intensity which is dependent on geographical factors. Commercialization of $\mathrm{CO}_{2}$ photoreduction could be relatively more challenging in countries or continents with lower solar intensity. For instance, the United Kingdom is reported to have an average solar irradiance of $101.2 \mathrm{~W} \mathrm{~m}^{-2}$, ranging from $71.8 \mathrm{~W} \mathrm{~m}^{-2}-128.4 \mathrm{~W} \mathrm{~m}^{-2}$ depending on the geographical location in the country (Burnett et al., 2014). This value is much lower as compared to tropical countries which has an average annual solar irradiance of approximately 10 -fold higher, ranging between 600 and $900 \mathrm{~W} \mathrm{~m}^{-2}$ (Mohammad et al., 2020). A higher level of solar irradiance is important to ensure that sufficient photon energy is available for activation of the photocatalyst to drive the $\mathrm{CO}_{2}$ reduction reaction (Sichel et al., 2017). As such, a higher performance photo(electrochemical)catalyst is necessary to overcome this barrier for the countries with lower solar irradiance.

With the increase in the awareness of sustainability processing, circular economy of the photoreduction system could be another focus of study. The efficiency of the photo(electrochemical) catalyst no doubt plays key role to these reaction pathways. However, one should not overlook the potential environmental impact of the use of the materials, if we are to upscale these technologies for large-scale reduction of $\mathrm{CO}_{2}$. In principal, a suitable photocatalyst material should not have significant impact to the environment, is green (or less toxic), and easy to handle. Extensive studies on the lifespan and reusability of photocatalyst materials could be the next focus to make this technology more economical and environmentally viable.

\section{CONCLUSION}

Photo-driven technologies are undoubtedly the most sustainable and green solution for the conversion of $\mathrm{CO}_{2}$ into energy-rich hydrocarbon derivatives. These processes

\section{REFERENCES}

Adams, F., Pschenitza, M., and Rieger, B. (2018). Yttrium-Catalyzed Synthesis of Bipyridine-Functionalized AB-Block Copolymers: Micellar Support for Photocatalytic Active Rhenium-Complexes. ChemCatChem 10, 4309-4316. doi:10.1002/cctc.201801009

Alsayegh, S. O., Varjian, R., Alsalik, Y., Katsiev, K., Isimjan, T. T., and Idriss, H. (2020). Methanol Production Using Ultrahigh Concentrated Solar Cells: Hybrid Electrolysis and $\mathrm{CO}_{2}$ Capture. ACS Energ. Lett. 5, 540-544. doi:10.1021/acsenergylett.9b02455

Andrei, V., Reuillard, B., and Reisner, E. (2020). Bias-free Solar Syngas Production by Integrating a Molecular Cobalt Catalyst with Perovskite- $\mathrm{BiVO}_{4}$ Tandems. Nat. Mater. 19, 189-194. doi:10.1038/s41563-019-0501-6 employ the power of the sun as the only resource to attain the Gibbs free energy of the $\mathrm{CO}_{2}$ reduction reaction; thus rendering it fossil fuel-free with markedly lower carbon footprint as compared to the conventional hydrothermal reactions or electrolysis. With the global pledge to achieve net zero-carbon emission by 2050, the development of emerging technologies in $\mathrm{CO}_{2}$ utilization must be fasttracked. In addition, with the recent interest in the exploration of Mars, a planet consisting of $95 \% \mathrm{CO}_{2}$ and a solar irradiation of $586 \mathrm{~W} \mathrm{~m}^{-2}$, it would be extremely beneficial to utilize its atmosphere to produce sustainable fuels for interplanetary travels. Despite great strides made in the field, the implementation and up-scaling of these photo-driven technologies for commercial applications remain a great hurdle even up till today. As highlighted in the previous sections, this is mainly ascribed to the constraints of solar energy potential as well as low product selectivity and yield. Intensified research is needed in the areas of materials discovery and innovative photoreactor designs. The resolution of these obstacles could bring about the successful industrialization of $\mathrm{CO}_{2}$ photoreduction technologies in the near future, which could ultimately pave the way for a greener and more sustainable tomorrow.

\section{DATA AVAILABILITY STATEMENT}

The original contributions presented in the study are included in the article/Supplementary Material, further inquiries can be directed to the corresponding author.

\section{AUTHOR CONTRIBUTIONS}

All authors listed have made a substantial, direct, and intellectual contribution to the work and approved it for publication.

\section{FUNDING}

This work was financially supported by Monash University Malaysia under the MUM-ASEAN Research Grant Scheme (Ref. no: ASE-000010).

Arai, T., Sato, S., Kajino, T., and Morikawa, T. (2013). Solar $\mathrm{CO}_{2}$ Reduction Using $\mathrm{H}_{2} \mathrm{O}$ by a Semiconductor/metal-Complex Hybrid Photocatalyst: Enhanced Efficiency and Demonstration of a Wireless System Using $\mathrm{SrTiO}_{3}$ Photoanodes. Energy Environ. Sci. 6, 1274-1282. doi:10.1039/ C3EE24317F

Arai, T., Sato, S., Sekizawa, K., Suzuki, T. M., and Morikawa, T. (2019). Solar-driven $\mathrm{CO}_{2}$ to $\mathrm{CO}$ Reduction Utilizing $\mathrm{H}_{2} \mathrm{O}$ as an Electron Donor by Earth-Abundant $\mathrm{Mn}$ Bipyridine Complex and Ni-Modified Fe-Oxyhydroxide Catalysts Activated in a Single-Compartment Reactor. Chem. Commun. 55, 237-240. doi:10.1039/ C8CC07900E

Arai, T., Tajima, S., Sato, S., Uemura, K., Morikawa, T., and Kajino, T. (2011). Selective $\mathrm{CO}_{2}$ Conversion to Formate in Water Using a CZTS Photocathode Modified with a Ruthenium Complex Polymer. Chem. Commun. 47, 12664-12666. doi:10.1039/C1CC16160A 
Burnett, D., Barbour, E., and Harrison, G. P. (2014). The UK Solar Energy Resource and the Impact of Climate Change. Renew. Energ. 71, 333-343. doi:10.1016/ j.renene.2014.05.034

Chen, S., Hai, G., Gao, H., Chen, X., Li, A., Zhang, X., et al. (2021). Modulation of the Charge Transfer Behavior of Ni(II)-doped $\mathrm{NH}_{2}$-MIL-125(Ti): Regulation of $\mathrm{Ni}$ Ions Content and Enhanced Photocatalytic $\mathrm{CO}_{2}$ Reduction Performance. Chem. Eng. J. 406, 126886. doi:10.1016/j.cej.2020.126886

Chen, W., Liu, X., Han, B., Liang, S., Deng, H., and Lin, Z. (2020). Boosted Photoreduction of Diluted $\mathrm{CO}_{2}$ through Oxygen Vacancy Engineering in $\mathrm{NiO}$ Nanoplatelets. Nano Res. 14, 730-737. doi:10.1007/s12274-020-3105-1

Cheng, W.-H., Richter, M. H., Sullivan, I., Larson, D. M., Xiang, C., Brunschwig, B. S., et al. (2020). $\mathrm{CO}_{2}$ Reduction to CO with $19 \%$ Efficiency in a Solar-Driven Gas Diffusion Electrode Flow Cell under Outdoor Solar Illumination. ACS Energ. Lett. 5, 470-476. doi:10.1021/acsenergylett.9b02576

Cheng, X., Dong, P., Huang, Z., Zhang, Y., Chen, Y., Nie, X., et al. (2017). Green Synthesis of Plasmonic Ag Nanoparticles Anchored $\mathrm{TiO}_{2}$ Nanorod Arrays Using Cold Plasma for Visible-Light-Driven Photocatalytic Reduction of $\mathrm{CO}_{2}$. J. $\mathrm{CO}_{2}$ Utilization 20, 200-207. doi:10.1016/j.jcou.2017.04.009

Creutzig, F., Agoston, P., Goldschmidt, J. C., Luderer, G., Nemet, G., and Pietzcker, R. C. (2017). The Underestimated Potential of Solar Energy to Mitigate Climate Change. Nat. Energ. 2, 17140. doi:10.1038/nenergy.2017.140

de Brito, J. F., Araujo, A. R., Rajeshwar, K., and Zanoni, M. V. B. (2015). Photoelectrochemical Reduction of $\mathrm{CO}_{2}$ on $\mathrm{Cu} / \mathrm{Cu}_{2} \mathrm{O}$ Films: Product Distribution and pH Effects. Chem. Eng. J. 264, 302-309. doi:10.1016/ j.cej.2014.11.081

Deb Nath, N. C., Choi, S. Y., Jeong, H. W., Lee, J.-J., and Park, H. (2016). Standalone Photoconversion of Carbon Dioxide on Copper Oxide Wire Arrays Powered by Tungsten Trioxide/dye-Sensitized Solar Cell Dual Absorbers. Nano Energy 25, 51-59. doi:10.1016/j.nanoen.2016.04.025

DuChene, J. S., Tagliabue, G., Welch, A. J., Cheng, W.-H., and Atwater, H. A. (2018). Hot Hole Collection and Photoelectrochemical $\mathrm{CO}_{2}$ Reduction with Plasmonic Au/p-GaN Photocathodes. Nano Lett. 18, 2545-2550. doi:10.1021/ acs.nanolett. $8 \mathrm{~b} 00241$

European Commission (). 2030 Climate \& Energy Framework. Available at: https:// ec.europa.eu/clima/policies/strategies/2030_en (Accessed June 25, 2021).

Fu, Q., Xiao, S., Li, Z., Li, Y., Kobayashi, H., Li, J., et al. (2018). Hybrid Solar-ToMethane Conversion System with a Faradaic Efficiency of up to 96. Nano Energy 53, 232-239. doi:10.1016/j.nanoen.2018.08.051

Fung, C.-M., Tang, J.-Y., Tan, L.-L., Mohamed, A. R., and Chai, S.-P. (2020). Recent Progress in Two-Dimensional Nanomaterials for Photocatalytic Carbon Dioxide Transformation into Solar Fuels. Mater. Today Sustainability 9, 100037. doi:10.1016/j.mtsust.2020.100037

Ghadimkhani, G., de Tacconi, N. R., Chanmanee, W., Janaky, C., and Rajeshwar, K. (2013). Efficient Solar Photoelectrosynthesis of Methanol from Carbon Dioxide Using Hybrid $\mathrm{CuO}-\mathrm{Cu}_{2} \mathrm{O}$ Semiconductor Nanorod Arrays. Chem. Commun. 49, 1297-1299. doi:10.1039/C2CC38068D

Gov, U. K. (2020). UK Sets Ambitious New Climate Target Ahead of UN Summit. Available at: https://www.gov.uk/government/news/uk-sets-ambitious-newclimate-target-ahead-of-un-summit (Accessed July 6, 2021).

Gurudayal, G., Bullock, J., Srankó, D. F., Towle, C. M., Lum, Y., Hettick, M., et al. (2017). Efficient Solar-Driven Electrochemical $\mathrm{CO}_{2}$ Reduction to Hydrocarbons and Oxygenates. Energ. Environ. Sci. 10, 2222-2230. doi:10.1039/C7EE01764B

Han, S.-G., Ma, D.-D., Zhou, S.-H., Zhang, K., Wei, W.-B., Du, Y., et al. (2021). Fluorine-tuned Single-Atom Catalysts with Dense Surface Ni-N4 Sites on Ultrathin Carbon Nanosheets for Efficient $\mathrm{CO}_{2}$ Electroreduction. Appl. Catal. B: Environ. 283, 119591. doi:10.1016/j.apcatb.2020.119591

He, Y., Rao, H., Song, K., Li, J., Yu, Y., Lou, Y., et al. (2019). 3D Hierarchical $\mathrm{ZnIn}_{2} \mathrm{~S}_{4}$ Nanosheets with Rich $\mathrm{Zn}$ Vacancies Boosting Photocatalytic $\mathrm{CO}_{2}$ Reduction. Adv. Funct. Mater. 29, 1905153. doi:10.1002/adfm.201905153

Hu, Y., Chen, F., Ding, P., Yang, H., Chen, J., Zha, C., et al. (2018). Designing Effective Si/Ag Interface via Controlled Chemical Etching for Photoelectrochemical $\mathrm{CO}_{2}$ Reduction. J. Mater. Chem. A. 6, 21906-21912. doi:10.1039/C8TA05420G

Huang, X., Shen, Q., Liu, J., Yang, N., and Zhao, G. (2016). A CO $\mathrm{CO}_{2}$ AdsorptionEnhanced Semiconductor/metal-Complex Hybrid Photoelectrocatalytic Interface for Efficient Formate Production. Energ. Environ. Sci. 9, 3161-3171. doi:10.1039/C6EE00968A
IEA (2021a). About CCUS. Paris: IEA. Available at: https://www.iea.org/reports/ about-ccus (Accessed Oct 19, 2021).

IEA (2021). Is Carbon Capture Too Expensive. Paris: IEA. Available at: https:// www.iea.org/commentaries/is-carbon-capture-too-expensive (Accessed Oct 15, 2021).

IEA (2019). Putting $\mathrm{CO}_{2}$ to Use: Creating Value from Emissions. Available at: https://www.oecd.org/publications/putting-co2-to-use-dfeabbf4-en.htm (Accessed June 25, 2021).

Jang, J.-W., Cho, S., Magesh, G., Jang, Y. J., Kim, J. Y., Kim, W. Y., et al. (2014). Aqueous-Solution Route to Zinc Telluride Films for Application to $\mathrm{CO}_{2}$ Reduction. Angew. Chem. Int. Ed. 53, 5852-5857. doi:10.1002/anie.201310461

Jang, Y. J., Jang, J.-W., Lee, J., Kim, J. H., Kumagai, H., Lee, J., et al. (2015). Selective CO Production by Au Coupled $\mathrm{ZnTe} / \mathrm{ZnO}$ in the Photoelectrochemical CO2 Reduction System. Energ. Environ. Sci. 8, 3597-3604. doi:10.1039/C5EE01445J

Jang, Y. J., Jeong, I., Lee, J., Lee, J., Ko, M. J., and Lee, J. S. (2016). Unbiased Sunlight-Driven Artificial Photosynthesis of Carbon Monoxide from $\mathrm{CO}_{2}$ Using a ZnTe-Based Photocathode and a Perovskite Solar Cell in Tandem. ACS Nano 10, 6980-6987. doi:10.1021/acsnano.6b02965

Jarvis, S. M., and Samsatli, S. (2018). Technologies and Infrastructures Underpinning Future $\mathrm{CO}_{2}$ Value Chains: A Comprehensive Review and Comparative Analysis. Renew. Sustain. Energ. Rev. 85, 46-68. doi:10.1016/ j.rser.2018.01.007

Jatav, S., Liu, J., Herber, M., and Hill, E. H. (2021). Facet Engineering of Bismuth Molybdate via Confined Growth in a Nanoscale Template toward Water Remediation. ACS Appl. Mater. Inter. 13, 18713-18723. doi:10.1021/ acsami.1c01144

Jeon, J. H., Mareeswaran, P. M., Choi, C. H., and Woo, S. I. (2014). Synergism between CdTe Semiconductor and Pyridine - Photoenhanced Electrocatalysis for $\mathrm{CO}_{2}$ reduction to Formic Acid. RSC Adv. 4, 3016-3019. doi:10.1039/ C3RA44410D

Jiang, Y., Liao, J.-F., Chen, H.-Y., Zhang, H.-H., Li, J.-Y., Wang, X.-D., et al. (2020). All-Solid-State Z-Scheme $\alpha-\mathrm{Fe}_{2} \mathrm{O}_{3} /$ Amine- $\mathrm{RGO} / \mathrm{CsPbBr}{ }_{3}$ Hybrids for VisibleLight-Driven Photocatalytic $\mathrm{CO}_{2}$ Reduction. Chem. 6, 766-780. doi:10.1016/ j.chempr.2020.01.005

Kaneco, S., Katsumata, H., Suzuki, T., and Ohta, K. (2006a). Photoelectrocatalytic Reduction of $\mathrm{CO}_{2}$ in LiOH/methanol at Metal-Modified P-InP Electrodes. Appl. Catal. B: Environ. 64, 139-145. doi:10.1016/j.apcatb.2005.11.012

Kaneco, S., Katsumata, H., Suzuki, T., and Ohta, K. (2006b). Photoelectrochemical Reduction of Carbon Dioxide at P-type Gallium Arsenide and P-type Indium Phosphide Electrodes in Methanol. Chem. Eng. J. 116, 227-231. doi:10.1016/ j.cej.2005.12.014

Kang, U., Choi, S. K., Ham, D. J., Ji, S. M., Choi, W., Han, D. S., et al. (2015). Photosynthesis of Formate from $\mathrm{CO}_{2}$ and Water at $1 \%$ Energy Efficiency via Copper Iron Oxide Catalysis. Energ. Environ. Sci. 8, 2638-2643. doi:10.1039/ C5EE01410G

Kang, U., and Park, H. (2017). A Facile Synthesis of $\mathrm{CuFeO}_{2}$ and $\mathrm{CuO}$ Composite Photocatalyst Films for the Production of Liquid Formate from $\mathrm{CO}_{2}$ and Water over a Month. J. Mater. Chem. A. 5, 2123-2131. doi:10.1039/C6TA09378G

Ke, X., Zhang, J., Dai, K., Fan, K., and Liang, C. (2021). Integrated S-Scheme Heterojunction of Amine-Functionalized 1D CdSe Nanorods Anchoring on Ultrathin 2D SnNb ${ }_{2} \mathrm{O}_{6}$ Nanosheets for Robust Solar-Driven $\mathrm{CO}_{2}$ Conversion. Sol. RRL 5, 2000805. doi:10.1002/solr.202000805

Kim, B., Seong, H., Song, J. T., Kwak, K., Song, H., Tan, Y. C., et al. (2019a). Over a $15.9 \%$ Solar-To-CO Conversion from Dilute $\mathrm{CO}_{2}$ Streams Catalyzed by Gold Nanoclusters Exhibiting a High $\mathrm{CO}_{2}$ Binding Affinity. ACS Energ. Lett 5, 749-757. doi:10.1021/acsenergylett.9b02511

Kim, J. H., Hansora, D., Sharma, P., Jang, J.-W., and Lee, J. S. (2019b). Toward Practical Solar Hydrogen Production - an Artificial Photosynthetic Leaf-ToFarm challenge. Chem. Soc. Rev. 48, 1908-1971. doi:10.1039/C8CS00699G

Kong, X. Y., Choo, Y. Y., Chai, S.-P., Soh, A. K., and Mohamed, A. R. (2016). Oxygen Vacancy Induced $\mathrm{Bi}_{2} \mathrm{WO}_{6}$ for the Realization of Photocatalytic $\mathrm{CO}_{2}$ Reduction over the Full Solar Spectrum: from the UV to the NIR Region. Chem. Commun. 52, 14242-14245. doi:10.1039/c6cc07750a

Kong, X. Y., Lee, W. Q., Mohamed, A. R., and Chai, S.-P. (2019). Effective Steering of Charge Flow through Synergistic Inducing Oxygen Vacancy Defects and P-N Heterojunctions in $2 \mathrm{D} / 2 \mathrm{D}$ Surface-Engineered $\mathrm{Bi}_{2} \mathrm{WO}_{6} / \mathrm{BiOI}$ cascade: Towards superior Photocatalytic $\mathrm{CO}_{2}$ Reduction Activity. Chem. Eng. J. 372, 1183-1193. doi:10.1016/j.cej.2019.05.001 
Kong, X. Y., Ng, B.-J., Tan, K. H., Chen, X., Wang, H., Mohamed, A. R., et al. (2018). Simultaneous Generation of Oxygen Vacancies on Ultrathin $\mathrm{BiOBr}$ Nanosheets during Visible-Light-Driven $\mathrm{CO}_{2}$ Photoreduction Evoked superior Activity and Long-Term Stability. Catal. Today 314, 20-27. doi:10.1016/ j.cattod.2018.04.018

Kong, X. Y., Tan, W. L., Ng, B.-J., Chai, S.-P., and Mohamed, A. R. (2017). Harnessing Vis-NIR Broad Spectrum for Photocatalytic $\mathrm{CO}_{2}$ Reduction over Carbon Quantum Dots-Decorated Ultrathin $\mathrm{Bi}_{2} \mathrm{WO}_{6}$ Nanosheets. Nano Res. 10, 1720-1731. doi:10.1007/s12274-017-1435-4

Kong, X. Y., Tong, T., Ng, B.-J., Low, J., Zeng, T. H., Mohamed, A. R., et al. (2020). Topotactic Transformation of Bismuth Oxybromide into Bismuth Tungstate: Bandgap Modulation of Single-Crystalline $\{001\}$-Faceted Nanosheets for Enhanced Photocatalytic $\mathrm{CO}_{2}$ Reduction. ACS Appl. Mater. Inter. 12, 26991-27000. doi:10.1021/acsami.9b15950

Kuk, S. K., Ham, Y., Gopinath, K., Boonmongkolras, P., Lee, Y., Lee, Y. W., et al. (2019). Continuous 3D Titanium Nitride Nanoshell Structure for Solar-Driven Unbiased Biocatalytic $\mathrm{CO}_{2}$ Reduction. Adv. Energ. Mater. 9, 1900029. doi:10.1002/aenm.201900029

Kumagai, H., Sahara, G., Maeda, K., Higashi, M., Abe, R., and Ishitani, O. (2017). Hybrid Photocathode Consisting of a $\mathrm{CuGaO}_{2}$ P-type Semiconductor and a $\mathrm{Ru}(\mathrm{ii})$-Re(i) Supramolecular Photocatalyst: Non-biased Visible-Light-Driven $\mathrm{CO}_{2}$ Reduction with Water Oxidation. Chem. Sci. 8, 4242-4249. doi:10.1039/ C7SC00940B

Kumaravel, V., Bartlett, J., and Pillai, S. C. (2020). Photoelectrochemical Conversion of Carbon Dioxide $\left(\mathrm{CO}_{2}\right)$ into Fuels and Value-Added Products. ACS Energ. Lett. 5, 486-519. doi:10.1021/acsenergylett.9b02585

Lee, K., Lee, S., Cho, H., Jeong, S., Kim, W. D., Lee, S., et al. (2018). $\mathrm{Cu}^{+}-$ incorporated $\mathrm{TiO}_{2}$ Overlayer on $\mathrm{Cu}_{2} \mathrm{O}$ Nanowire Photocathodes for Enhanced Photoelectrochemical Conversion of $\mathrm{CO}_{2}$ to Methanol. J. Energ. Chem. 27, 264-270. doi:10.1016/j.jechem.2017.04.019

Lee, S., Kim, S., Park, C., Moon, G.-h., Son, H.-J., Baeg, J.-O., et al. (2020). NafionAssisted Noncovalent Assembly of Molecular Sensitizers and Catalysts for Sustained Photoreduction of $\mathrm{CO}_{2}$ to CO. ACS Sustain. Chem. Eng. 8, 3709-3717. doi:10.1021/acssuschemeng.9b06797

Lee, S. Y., Lim, S. Y., Seo, D., Lee, J.-Y., and Chung, T. D. (2016). Light-Driven Highly Selective Conversion of $\mathrm{CO}_{2}$ to Formate by Electrosynthesized Enzyme/ Cofactor Thin Film Electrode. Adv. Energ. Mater. 6, 1502207. doi:10.1002/ aenm.201502207

Li, L., Zhang, Z., Ding, C., and Xu, J. (2021a). Boosting Charge Separation and Photocatalytic $\mathrm{CO}_{2}$ Reduction of $\mathrm{CsPbBr}_{3}$ Perovskite Quantum Dots by Hybridizing with P3HT. Chem. Eng. J. 419, 129543. doi:10.1016/ j.cej.2021.129543

Li, S., Wang, C., Liu, Y., Xue, B., Jiang, W., Liu, Y., et al. (2021b). Photocatalytic Degradation of Antibiotics Using a Novel Ag/ $\mathrm{Ag}_{2} \mathrm{~S} / \mathrm{Bi}_{2} \mathrm{MoO}_{6}$ Plasmonic P-N Heterojunction Photocatalyst: Mineralization Activity, Degradation Pathways and Boosted Charge Separation Mechanism. Chem. Eng. J. 415, 128991. doi:10.1016/j.cej.2021.128991

Liu, W., Li, X., Wang, C., Pan, H., Liu, W., Wang, K., et al. (2019). A Scalable General Synthetic Approach toward Ultrathin Imine-Linked TwoDimensional Covalent Organic Framework Nanosheets for Photocatalytic $\mathrm{CO}_{2}$ Reduction. J. Am. Chem. Soc. 141, 17431-17440. doi:10.1021/jacs.9b09502

Lu, D., Kumar Kondamareddy, K., Fan, H., Gao, B., Wang, J., Wang, J., et al. (2019). Highly Improved Visible-Light-Driven Photocatalytic Removal of $\mathrm{Cr}$ (VI) over Yttrium Doped H-Titanate Nanosheets and its Synergy with Organic Pollutant Oxidation. Separat. Purif. Technol. 210, 775-785. doi:10.1016/ j.seppur.2018.09.004

Miao, Y.-F., Guo, R.-T., Gu, J.-W., Liu, Y.-Z., Wu, G.-l., Duan, C.-P., et al. (2021). Oxygen Vacancy-Rich $\mathrm{BiO}_{2}$-X: Super-active Co-catalyst on $\mathrm{G}-\mathrm{C}_{3} \mathrm{n}_{4}$ for Efficient Visible-Light Photocatalytic $\mathrm{CO}_{2}$ Reduction. J. $\mathrm{CO}_{2}$ Utilization 44, 101377. doi:10.1016/j.jcou.2020.101377

Mohammad, S. T., Al-Kayiem, H. H., Aurybi, M. A., and Khlief, A. K. (2020). Measurement of Global and Direct normal Solar Energy Radiation in Seri Iskandar and Comparison with Other Cities of Malaysia. Case Stud. Therm. Eng. 18, 100591. doi:10.1016/j.csite.2020.100591

Muhammad, A., Tahir, M., Al-Shahrani, S. S., Mahmood Ali, A., and Rather, S. U. (2020). Template Free Synthesis of Graphitic Carbon Nitride Nanotubes Mediated by Lanthanum (La/g-CNT) for Selective Photocatalytic $\mathrm{CO}_{2}$
Reduction via Dry Reforming of Methane (DRM) to Fuels. Appl. Surf. Sci. 504, 144177. doi:10.1016/j.apsusc.2019.144177

Pan, B., Wu, Y., Rhimi, B., Qin, J., Huang, Y., Yuan, M., et al. (2021). Oxygen-

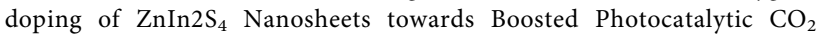
Reduction. J. Energ. Chem. 57, 1-9. doi:10.1016/j.jechem.2020.08.024

Qiu, J., Zeng, G., Ha, M.-A., Ge, M., Lin, Y., Hettick, M., et al. (2015). Artificial Photosynthesis on $\mathrm{TiO}_{2}$-Passivated InP Nanopillars. Nano Lett. 15, 6177-6181. doi:10.1021/acs.nanolett.5b02511

Rao, K. R., Pishgar, S., Strain, J., Kumar, B., Atla, V., Kumari, S., et al. (2018). Photoelectrochemical Reduction of $\mathrm{CO}_{2}$ to $\mathrm{HCOOH}$ on Silicon Photocathodes with Reduced $\mathrm{SnO}_{2}$ Porous Nanowire Catalysts. J. Mater. Chem. A. 6, 1736-1742. doi:10.1039/C7TA09672K

Raziq, F., Qu, Y., Humayun, M., Zada, A., Yu, H., and Jing, L. (2017). Synthesis of $\mathrm{SnO}_{2}$ /B-P Codoped G- $\mathrm{C}_{3} \mathrm{n}_{4}$ Nanocomposites as Efficient Cocatalyst-free Visible-Light Photocatalysts for $\mathrm{CO}_{2}$ Conversion and Pollutant Degradation. Appl. Catal. B: Environ. 201, 486-494. doi:10.1016/ j.apcatb.2016.08.057

Schreier, M., Curvat, L., Giordano, F., Steier, L., Abate, A., Zakeeruddin, S. M., et al. (2015). Efficient Photosynthesis of Carbon Monoxide from $\mathrm{CO}_{2}$ Using Perovskite Photovoltaics. Nat. Commun. 6, 1-6. doi:10.1038/ncomms8326

Schreier, M., Héroguel, F., Steier, L., Ahmad, S., Luterbacher, J. S., Mayer, M. T., et al. (2017). Solar Conversion of $\mathrm{CO}_{2}$ to $\mathrm{CO}$ Using Earth-Abundant Electrocatalysts Prepared by Atomic Layer Modification of CuO. Nat. Energ. 2, 1-9. doi:10.1038/nenergy.2017.87

Sekimoto, T., Hashiba, H., Shinagawa, S., Uetake, Y., Deguchi, M., Yotsuhashi, S., et al. (2016). Analysis of Products from Photoelectrochemical Reduction of $13 \mathrm{CO}_{2}$ by GaN-Si Based Tandem Photoelectrode. J. Phys. Chem. C 120, 13970-13975. doi:10.1021/acs.jpcc.6b03840

Sekizawa, K., Sato, S., Arai, T., and Morikawa, T. (2018). Solar-Driven Photocatalytic $\mathrm{CO}_{2}$ Reduction in Water Utilizing a Ruthenium Complex Catalyst on P-type $\mathrm{Fe}_{2} \mathrm{O}_{3}$ with a Multiheterojunction. ACS Catal. 8, 1405-1416. doi:10.1021/acscatal.7b03244

Sichel, C., Tello, J., de Cara, M., and Fernández-Ibáñez, P. (2007). Effect of UV Solar Intensity and Dose on the Photocatalytic Disinfection of Bacteria and Fungi. Catal. Today 129, 152-160. doi:10.1016/j.cattod.2007.06.061

Sokol, K. P., Robinson, W. E., Oliveira, A. R., Warnan, J., Nowaczyk, M. M., Ruff, A., et al. (2018). Photoreduction of $\mathrm{CO}_{2}$ with a Formate Dehydrogenase Driven by Photosystem II Using a Semi-artificial Z-Scheme Architecture. J. Am. Chem. Soc. 140, 16418-16422. doi:10.1021/jacs.8b10247

Sun, Z., Fang, W., Zhao, L., and Wang, H. (2020). 3D Porous Cu-NPs/g- $\mathrm{C}_{3} \mathrm{n}_{4}$ Foam with Excellent $\mathrm{CO}_{2}$ Adsorption and Schottky junction Effect for Photocatalytic $\mathrm{CO}_{2}$ Reduction. Appl. Surf. Sci. 504, 144347. doi:10.1016/j.apsusc.2019.144347

Tan, L. L., Ong, W. J., Chai, S. P., and Mohamed, A. R. (2017). Photocatalytic Reduction of $\mathrm{CO}_{2}$ with $\mathrm{H}_{2} \mathrm{O}$ over Greaphene Oxide-Supported OxygenRich $\mathrm{TiO}_{2}$ Hybrid Photocatalyst under Visible Light Irradiation: Process and Kinetic Studies. Chem. Eng. J. 308, 245-255. doi:10.1016/ j.cej.2016.09.050

Teh, Y. W., Fung, C.-M., Chee, M. K. T., Low, J., Yong, S.-T., and Chai, S.-P. (2021). Broadening Cognizance on Atomically Thin Photocatalysts. Mater. Today 43, 198-212. doi:10.1016/j.mattod.2020.10.034

The Global $\mathrm{CO}_{2}$ Initiative (2016). Global Roadmap for Implementing $\mathrm{CO}_{2}$ Utilization. Available at: https://assets.ctfassets.net/xg0gvlarhdr3/27vQZEvrxaQiQEAsGyoSQu/ 44ee0b72ceb9231ec53ed180cb759614/CO2U_ICEF_Roadmap_FINAL_2016_12_ 07.pdf (Assessed September 26, 2021).

Thompson, W. A., Sanchez Fernandez, E., and Maroto-Valer, M. M. (2020). Probability Langmuir-Hinshelwood Based $\mathrm{CO}_{2}$ Photoreduction Kinetic Models. Chem. Eng. J. 384, 123356. doi:10.1016/j.cej.2019.123356

Ulmer, U., Dingle, T., Duchesne, P. N., Morris, R. H., Tavasoli, A., Wood, T., et al. (2019). Fundamentals and Applications of Photocatalytic $\mathrm{CO}_{2}$ Methanation. Nat. Commun. 10, 3169. doi:10.1038/s41467-019-10996-2

United Nations Climate Change (2009). Copenhagen Climate Change Conference December 2009. Available at: https://unfccc.int/process-and-meetings/ conferences/past-conferences/copenhagen-climate-change-conference-december2009/copenhagen-climate-change-conference-december-2009 (Accessed Sept 15, 2021).

United Nations Climate Change (). The Paris Agreement. Available at: https:// unfccc.int/process-and-meetings/the-paris-agreement/the-paris-agreement (Accessed Sept 15, 2021). 
United Nations Climate Change (). What Is the Kyoto Protocol. Available at: https://unfccc.int/kyoto_protocol (Accessed June 24, 2021).

Wang, F., Liu, D., Wen, J., and Zheng, X. (2021). In-situ Sulfurized $\operatorname{In}_{2} \mathrm{~S}_{3} / \mathrm{MoO}_{3} @$ $\mathrm{MoS}_{2}$ Heterojunction for Visible Light Induced $\mathrm{CO}_{2}$ Photoreduction. J. Environ. Chem. Eng. 9, 106042. doi:10.1016/j.jece.2021.106042

Wang, H.-N., Zou, Y.-H., Sun, H.-X., Chen, Y., Li, S.-L., and Lan, Y.-Q. (2021a). Recent Progress and Perspectives in Heterogeneous Photocatalytic $\mathrm{CO}_{2}$ Reduction through a Solid-Gas Mode. Coord. Chem. Rev. 438, 213906. doi:10.1016/j.ccr.2021.213906

Wang, J., Wang, J., Li, N., Du, X., Ma, J., He, C., et al. (2020a). Direct Z-Scheme 0D/ 2D Heterojunction of $\mathrm{CsPbBr}_{3}$ Quantum Dots $/ \mathrm{Bi}_{2} \mathrm{WO}_{6}$ Nanosheets for Efficient Photocatalytic $\mathrm{CO}_{2}$ Reduction. ACS Appl. Mater. Inter. 12, 31477-31485. doi:10.1021/acsami.0c08152

Wang, Q., Warnan, J., Rodríguez-Jiménez, S., Leung, J. J., Kalathil, S., Andrei, V., et al. (2020b). Molecularly Engineered Photocatalyst Sheet for Scalable Solar Formate Production from Carbon Dioxide and Water. Nat. Energ. 5, 703-710. doi:10.1038/s41560-020-0678-6

Wang, Y., Zhang, Y., Chen, Y., Li, Z., and Zou, Z. (2021b). Lanthanum Bismuth Oxide Photocatalysts for $\mathrm{CO}_{2}$ Reduction to $\mathrm{CO}$ with High Selectivity. Sustain. Energ. Fuels 5, 2688-2694. doi:10.1039/D1SE00245G

Won, D. H., Choi, C. H., Chung, J., and Woo, S. I. (2014). Photoelectrochemical Production of Formic Acid and Methanol from Carbon Dioxide on MetalDecorated $\mathrm{CuO} / \mathrm{Cu}_{2} \mathrm{O}$-Layered Thin Films under Visible Light Irradiation. Appl. Catal. B: Environ. 158-159, 217-223. doi:10.1016/j.apcatb.2014.04.021

Wu, H., Kong, X. Y., Wen, X., Chai, S. P., Lovell, E. C., Tang, J., et al. (2021). MetalOrganic Framework Decorated Cuprous Oxide Nanowires for Long-lived Charges Applied in Selective Photocatalytic $\mathrm{CO}_{2}$ Reduction to $\mathrm{CH}_{4}$. Angew. Chem. Int. Ed. 60, 8455-8459. doi:10.1002/anie.202015735

Xiao, S., Li, Z., Fu, Q., Li, Y., Li, J., Zhang, L., et al. (2020). Hybrid Microbial Photoelectrochemical System Reduces $\mathrm{CO}_{2}$ to $\mathrm{CH}_{4}$ with $1.28 \%$ Solar Energy Conversion Efficiency. Chem. Eng. J. 390, 124530. doi:10.1016/j.cej.2020.124530

Xiong, Z., Zhao, Y., Zhang, J., and Zheng, C. (2015). Efficient Photocatalytic Reduction of $\mathrm{CO}_{2}$ into Liquid Products over Cerium Doped Titania Nanoparticles Synthesized by a Sol-Gel Auto-Ignited Method. Fuel Process. Technol. 135, 6-13. doi:10.1016/j.fuproc.2014.09.017

Xu, K., Chatzitakis, A., Backe, P. H., Ruan, Q., Tang, J., Rise, F., et al. (2021). In Situ cofactor Regeneration Enables Selective $\mathrm{CO}_{2}$ Reduction in a Stable and Efficient
Enzymatic Photoelectrochemical Cell. Appl. Catal. B: Environ. 296, 120349. doi:10.1016/j.apcatb.2021.120349

Ye, T., Huang, W., Zeng, L., Li, M., and Shi, J. (2017). $\mathrm{CeO}_{2}-\mathrm{x}$ Platelet from Monometallic Cerium Layered Double Hydroxides and its Photocatalytic Reduction of $\mathrm{CO}_{2}$. Appl. Catal. B: Environ. 210, 141-148. doi:10.1016/ j.apcatb.2017.03.051

Zeng, G., Qiu, J., Hou, B., Shi, H., Lin, Y., Hettick, M., et al. (2015). Enhanced Photocatalytic Reduction of $\mathrm{CO}_{2}$ to $\mathrm{CO}$ through $\mathrm{TiO}_{2}$ Passivation of InP in Ionic Liquids. Chem. Eur. J. 21, 13502-13507. doi:10.1002/ chem.201501671

Zhou, B., Kong, X., Vanka, S., Cheng, S., Pant, N., Chu, S., et al. (2019). A GaN:Sn Nanoarchitecture Integrated on a Silicon Platform for Converting $\mathrm{CO}_{2}$ to $\mathrm{HCOOH}$ by Photoelectrocatalysis. Energ. Environ. Sci. 12, 2842-2848. doi:10.1039/C9EE01339C

Zhou, X., Liu, R., Sun, K., Chen, Y., Verlage, E., Francis, S. A., et al. (2016). Solardriven Reduction of $1 \mathrm{Atm}$ of $\mathrm{CO}_{2}$ to Formate at $10 \%$ Energy-Conversion Efficiency by Use of a $\mathrm{TiO}_{2}$-Protected III-V Tandem Photoanode in Conjunction with a Bipolar Membrane and a Pd/C Cathode. ACS Energ. Lett 1, 764-770. doi:10.1021/acsenergylett.6b00317

Conflict of Interest: The authors declare that the research was conducted in the absence of any commercial or financial relationships that could be construed as a potential conflict of interest.

Publisher's Note: All claims expressed in this article are solely those of the authors and do not necessarily represent those of their affiliated organizations, or those of the publisher, the editors and the reviewers. Any product that may be evaluated in this article, or claim that may be made by its manufacturer, is not guaranteed or endorsed by the publisher.

Copyright (C) 2021 Gui, Lee, Putri, Kong, Tan and Chai. This is an open-access article distributed under the terms of the Creative Commons Attribution License (CC BY). The use, distribution or reproduction in other forums is permitted, provided the original author(s) and the copyright owner(s) are credited and that the original publication in this journal is cited, in accordance with accepted academic practice. No use, distribution or reproduction is permitted which does not comply with these terms. 